\title{
STATCOM controllers based on fuzzy PI approach
}

\author{
Tamer M. Shehata ${ }^{1}$, Mohamed S. Abdul moteleb ${ }^{2}$, Essam Abou El-Zahab ${ }^{3}$ \\ ${ }^{1,2}$ Department of Power Electronics, Electronics Research Institute at Cairo City, Egypt \\ ${ }^{3}$ Department of Electrical Engineering, Cairo University, Egypt
}

\section{Article Info}

Article history:

Received Oct 1, 2019

Revised Dec 3, 2019

Accepted Dec 17, 2019

\section{Keywords: \\ Dc-bus voltage \\ Fuzzy \\ PI}

STATCOM

Transient stability

\begin{abstract}
The electricity companies enforced some legislation on the electricity consumption contracts because the electricity network cannot bear the increasing demands of consumers. Therefore, a new controlling system is required to improve the frequent variations of the power system operating point (OP). Consequently, the flexible AC transmission systems (FACTS) controllers should be able to integrate with recent OP. Coordination of FACTS controller is more sophisticated due to various OP and uncertainties parametric in cooperation with the non linearity of power system (PS). Static Synchronous Compensator (STATCOM) plays very important role like the stability support of large and small transient-disturbance in PS. Therefore, the aim of this research is presents fuzzy logic (FL) with the PI controller (a novel controller) its ability to improve the performance of the power system along with the capability of switch irregular and rough actual world data. This new controlling system may be suitable for a wide range of applications especially the models which deal with huge and complicated data analysis. This new controller system carries out the adjustments of the voltage on DC capacitor under transient and steady-state conditions.
\end{abstract}

Copyright $\odot 2020$ Institute of Advanced Engineering and Science. All rights reserved.

\section{Corresponding Author:}

Tamer M. Shehata,

Electronics Research Institute,

New Egypt City, Cairo, Egypt.

Email: tamer_shehata@eri.sci.eg

\section{INTRODUCTION}

Recently, the unbalance of current (I) and voltage (V) attarcts more consideration through the growing awareness of the power quality. Unbalances between $\mathrm{V}$ and I of a 3-Ph power system have always been an important issue that faces experts in power engineering where the unbalance in the supply voltage may enforce the power converter to generate additional harmonic distortions. They might cause a malfunction of sensitive 3-Ph electronic equipment. In fact, the $\mathrm{V}$ and I unbalances have been considered as one of the basic attributes of power quality [1]. A certain degrees of unbalances in a real power system can be produced due to asymmetry in the loads and transmission-lines. Keeping this in mind, small quantities of negative (-ve) and zero-sequence voltages may be noticed in the power networks and are regarded as disturbances whose levels have to be controlled in order to retain the system's electromagnetic compatibility [2]. To grow the usable power transmission capacity (UPTC) and to face such problem types, FACTS were evolved and presented to the market.

Hingorani introduced the philosophy of FACTS [3] with FACTS devices' objective of bringing the system under control and transmitting the power as oriented by the control centre and allowing the increase of the UPTC to its predetermined thermal-limits. Phase-angles and magnitudes of the voltages at the selected buses and/or line impedances can be controlled, thanks to FACTS devices [4]. Latest developments of power electronics introduce the usage of FACTS controllers in the power systems [5]. FACTS technology offers the chance of [6]: 
a) Preventing blackouts.

b) Reducing the circulating reactive power.

c) Improving the limits of the system stability.

d) Reducing the system oscillations and damping.

e) Reducing the voltage flickering.

f) Controlling the power flow.

In ancient times, numerous control procedures with different strategies (e.g fuzzy logic (FL) control, sliding-mode control [7, 8] and Radial Basis Function Neural Network (RBFNN) ) were applied to improve the transient stability [9, 10]. Some of these control approaches are based upon the Lyapunov's second law [11]. A novel control strategy for a UPFC for the first-swing angles' propagation period is presented in Mamdani's review [12]. A great deal of the techniques for stability analysis and damping controllers is model based which means that the system dynamics must be identified [13].

However, it is complex to model systems exactly the same. The FL controller (FLC) is commonly designed based upon the behavior of the system and without a need to attain the exact model. A vital demerit of FLC is that it could not adjust its control parameters for a better performance in different conditions. Opposed to FLCs, the learning algorithm is an essential ability of the neural-networks thus; neuro-fuzzy systems can be built from the combination of these two systems. But this is difficult and have some disadvantage affects on the systems performance. Therefore, in this research, an FLC in addition to PI controller are proposed for controlling Vdc bus parameter of a STATCOM in compensation-mode under transient and steady conditions. The performances of the proposed controller are carried out by Simulations using MATLAB/SIMULINK. The advantages of the proposed controller will be clarified through the curent results.

\section{PRINCIPLE OPERATION OF STATCOM}

The parallel plate actuator is under two forces, the electrostatic force caused by the attraction between the plates and the mechanical force caused by the cantilever as shown in the schematic Figure 1. Hence, the net force between these two forces determines the position of the movable plate. The equation of the actuator in standard form as a second order system is STATCOM. It is the source of Q controlled, which provide the desired absorption and generation $\mathrm{Q}$ through a current waveform and voltage of electronics processing in voltage source converters (VSC).

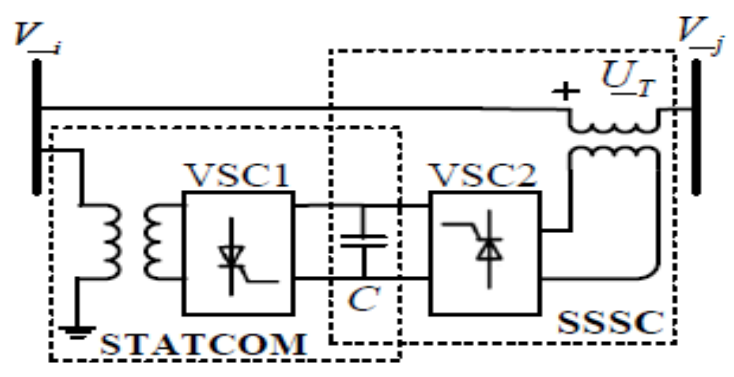

Figure 1. Simple structure of SSSC, STATCOM and UPFC

In Figure 2a a STATCOM power single line circuit is shown, while a VSC is linked to the bus of utility throughout magnetic coupling. In Figure $2 b$ shunt reactors and capacitor banks are not required for absorption and generation of Q due to a STATCOM which seen as a reactance after an adjustable VSC, thus giving a STATCOM low magnetic-impacts, compacted design, otherwise small footprints and low noise. Figure $2 \mathrm{c}$ illustrates the Q exchange between the AC-system and converter which is able to be control by changeable amplitude of output voltage of the 3-Ph, Es.

Specifically, when the utilities' bus voltage (Et) amplitude is below the Es amplitude, the I flow is conveyed from the converter to $\mathrm{AC}$-systems during the reactance and capacitive $\mathrm{Q}$ will be generated by the converter to the AC-system. In contrast, if the Et amplitude increased above the Es amplitude, the I flow conveyed from the AC-system to a converter and the inductive $\mathrm{Q}$ will be absorbed by the converter from AC-system. If the Et amplitude equals the Es amplitude, the Q exchange equals zero. The STATCOM in this case is assumed in floating state [14-18]. 
The objective of this research is to how to define the kind of FACTS devices that must be installed under altered variations in the network in accordance to Figure 3. The discussion will include, in details, the cases which are caused by the thermal limits (e.g. High voltage (HV) at low-load, low voltage (LV) at heavy-load, LV following an outage and HV following at outage). The STATCOM with fuzzy controller to save the system in stability under different conditions will be employed.

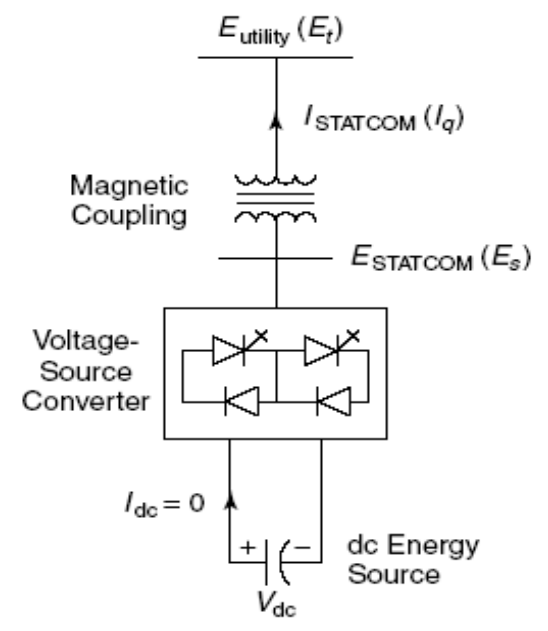

(a)

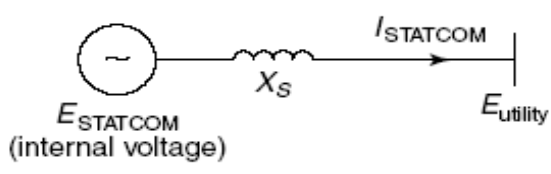

(b)

Figure 2. Principle diagram of STATCOM: (a) power -circuit; (b) equivalent -circuit; and (c) exchange of power

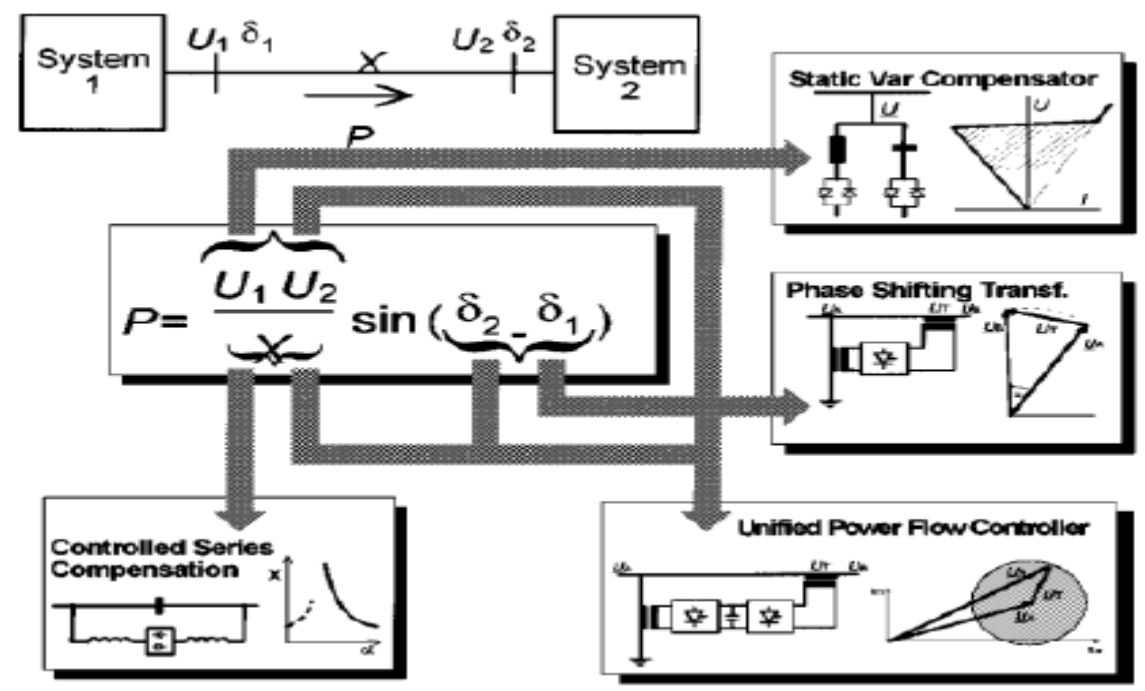

Figure 3. Power flow control and stability improvement in AC systems

\section{MODEL OF STATCOM STEADY STATE}

Always AC-system is connected with STATCOM in parallel through magnetic coupling represented by resistance (Rs), and leakage-inductance (Ls) [19-23]. Figure 4 illustrates a classic connection of STATCOM, which consists of a capacitor (Cs) as energy storage equipment at DC-side. The VSC use also IGBT or GTO as a switching equipment. The Cs in shunt with resistance (Rp) represents both losses switching and capacitor. 

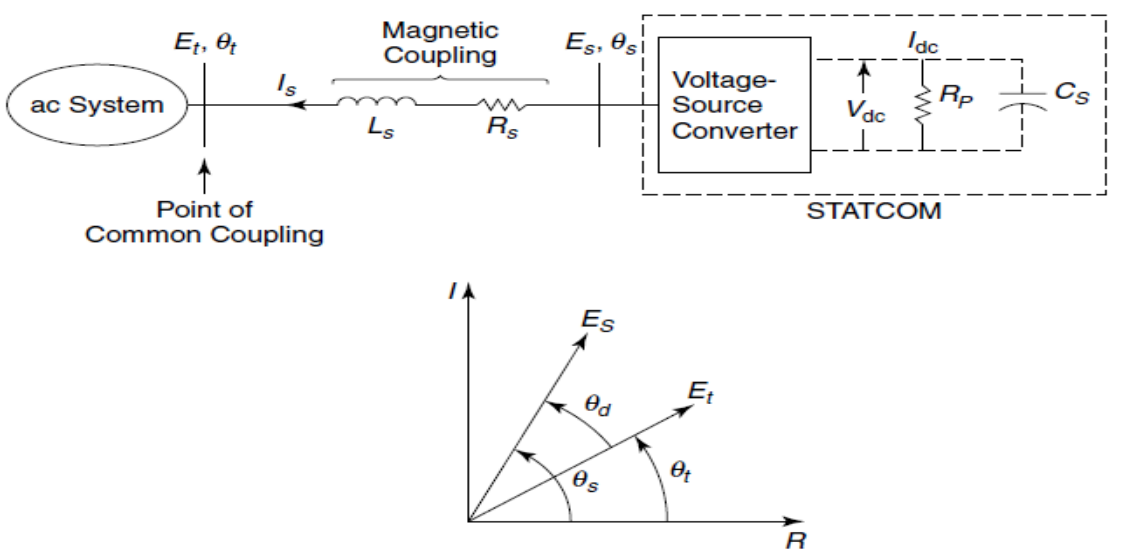

Figure 4. A classical connection of STATCOM to the ac-system

From Figure (4), it is clear that the AC-side of STATCOM circuit can be written as first order differential-equations as follows:

$$
\begin{aligned}
& \frac{\mathrm{di}_{\mathrm{sa}}}{\mathrm{dt}}=\frac{1}{\mathrm{~L}}\left(-\mathrm{R}_{\mathrm{s}} \mathrm{i}_{\mathrm{sa}}+\mathrm{e}_{\mathrm{sa}}-\mathrm{e}_{\mathrm{ta}}\right) \\
& \frac{\mathrm{di_{sb }}}{\mathrm{dt}}=\frac{1}{\mathrm{~L}}\left(-\mathrm{R}_{\mathrm{s}} \mathrm{i}_{\mathrm{sb}}+\mathrm{e}_{\mathrm{sb}}-\mathrm{e}_{\mathrm{tb}}\right) \\
& \frac{\mathrm{di_{sc }}}{\mathrm{dt}}=\frac{1}{\mathrm{~L}}\left(-\mathrm{R}_{\mathrm{s}} \mathrm{i}_{\mathrm{sc}}+\mathrm{e}_{\mathrm{sc}}-\mathrm{e}_{\mathrm{tc}}\right)
\end{aligned}
$$
are obtained:

By converting these equations in R-I frame of reference (Kundur, 1994), the following equations

$$
\left[\begin{array}{c}
\cdot \\
I_{s R} \\
\dot{I_{s I}}
\end{array}\right]=\left[\begin{array}{cc}
\frac{-R_{s}}{L_{s}} & w_{o} \\
-w_{o} & \frac{-R_{s}}{L_{s}}
\end{array}\right]\left[\begin{array}{c}
I_{s R} \\
I_{s I}
\end{array}\right]+\frac{1}{L_{s}}\left[\begin{array}{c}
E_{s R}-E_{t R} \\
E_{s I}-E_{t I}
\end{array}\right]
$$

The dc-side of STATCOM circuit equation as follows:

$$
\frac{d V_{d c}}{d_{t}}=\frac{-1}{C_{s}}\left(I_{d c}+\frac{d V_{d c}}{R_{P}}\right)
$$

The equation of power balance given when the converter instant powers at the DC and AC terminals are equal is as follows:

$$
\mathrm{V}_{\mathrm{dc}} \mathrm{I}_{\mathrm{dc}}=\frac{3}{2}\left(\mathrm{E}_{\mathrm{sR}} \mathrm{I}_{\mathrm{sR}}+\mathrm{E}_{\mathrm{sI}} \mathrm{I}_{\mathrm{sI}}\right)
$$

Where, $3 / 2$ is transformation constant of R-I frame.

Derived from phasor- diagram illustrated in Figure 5, the $\mathrm{E}_{\mathrm{SR}}$ and $\mathrm{E}_{\mathrm{SI}} \mathrm{can}$ be defined as follows:

$$
\begin{aligned}
& E_{s R}=E_{s} \cos \theta_{s}=K_{c s} V_{d c} \cos \theta_{s} \\
& E_{s I}=E_{s} \sin \theta_{s}=K_{c s} V_{d c} \sin \theta_{s}
\end{aligned}
$$

Where: $\mathrm{K}_{\mathrm{CS}}$ is constant pertaining between the $\mathrm{DC}$ and $\mathrm{AC}$ voltages.

In a VSC of 12 pulses, the $\mathrm{K}_{\mathrm{cs}}=2 \sqrt{6 \pi}$. Therefore, (4) becomes:

$$
\begin{aligned}
& \mathrm{V}_{\mathrm{dc}} \mathrm{I}_{\mathrm{dc}}=\frac{3}{2}\left(\mathrm{~K}_{\mathrm{cs}} \mathrm{V}_{\mathrm{dc}} \cos \theta_{\mathrm{s}} \mathrm{I}_{\mathrm{sR}}+\mathrm{K}_{\mathrm{cs}} \mathrm{V}_{\mathrm{dc}} \sin \theta_{\mathrm{s}} \mathrm{I}_{\mathrm{sI}}\right) \\
& \mathrm{I}_{\mathrm{dc}}=\frac{3}{2}\left(\mathrm{~K}_{\mathrm{cs}} \cos \theta_{\mathrm{s}} \mathrm{I}_{\mathrm{sR}}+\mathrm{K}_{\mathrm{cs}} \sin \theta_{\mathrm{s}} \mathrm{I}_{\mathrm{sI}}\right)
\end{aligned}
$$

By substitution, the value of Idc in equation (3) is as follows, 


$$
\frac{d V_{d c}}{d_{t}}=\frac{-1}{c_{s}}\left(\frac{3}{2}\left(K_{c s} \cos \theta_{s} I_{s R}+K_{c s} \sin \theta_{s} I_{s I}\right)+\frac{d V_{d c}}{R_{P}}\right)
$$

Substitute the values of $\mathbf{E}_{s I}$ and $\mathbf{E}_{s \mathbf{R}}$ from (5) into (2), one may obtain:

$$
\left[\begin{array}{c}
\cdot \cdot \\
\mathrm{I}_{\mathrm{sR}} \\
\dot{\mathrm{I}_{\mathrm{sI}}}
\end{array}\right]=\left[\begin{array}{cc}
\frac{-\mathrm{R}_{\mathrm{s}}}{\mathrm{L}_{\mathrm{s}}} & \mathrm{w}_{\mathrm{o}} \\
-\mathrm{w}_{\mathrm{o}} & \frac{-\mathrm{R}_{\mathrm{s}}}{\mathrm{L}_{\mathrm{s}}}
\end{array}\right]\left[\begin{array}{c}
\mathrm{I}_{\mathrm{sR}} \\
\mathrm{I}_{\mathrm{sI}}
\end{array}\right]+\frac{1}{\mathrm{~L}_{\mathrm{s}}}\left[\begin{array}{c}
\mathrm{K}_{\mathrm{cs}} \mathrm{V}_{\mathrm{dc}} \cos \theta_{\mathrm{s}}-\mathrm{E}_{\mathrm{tR}} \\
\mathrm{K}_{\mathrm{cs}} \mathrm{V}_{\mathrm{dc}} \sin \theta_{\mathrm{s}}-\mathrm{E}_{\mathrm{tI}}
\end{array}\right]
$$
as follows:

STATCOM circuit in Figure 5 can be modeled by state space in R-I frame derived from (8) and (9)

$$
\left[\begin{array}{c}
\dot{\mathrm{I}_{\mathrm{sR}}} \\
\dot{\mathrm{I}_{\mathrm{SI}}} \\
\dot{\mathrm{V}_{\mathrm{dc}}}
\end{array}\right]=\left[\begin{array}{ccc}
\frac{-\mathrm{R}_{\mathrm{s}}}{\mathrm{L}_{\mathrm{s}}} & \mathrm{w}_{\mathrm{o}} & \frac{\mathrm{K}_{\mathrm{cs}} \cos \theta_{\mathrm{s}}}{\mathrm{L}_{\mathrm{s}}} \\
-\mathrm{w}_{\mathrm{O}} & \frac{-\mathrm{R}_{\mathrm{s}}}{\mathrm{L}_{\mathrm{s}}} & \frac{\mathrm{K}_{\mathrm{cs}} \sin \theta_{\mathrm{s}}}{\mathrm{L}_{\mathrm{s}}} \\
\frac{-1.5 \mathrm{~K}_{\mathrm{cs}} \cos \theta_{\mathrm{s}}}{\mathrm{C}_{\mathrm{s}}} & \frac{-1.5 \mathrm{~K}_{\mathrm{cs}} \cos \theta_{\mathrm{s}}}{\mathrm{C}_{\mathrm{s}}} & \frac{-1}{\mathrm{R}_{\mathrm{P}} \mathrm{C}_{\mathrm{s}}}
\end{array}\right]\left[\begin{array}{c}
\mathrm{I}_{\mathrm{sR}} \\
\mathrm{I}_{\mathrm{SI}} \\
\mathrm{V}_{\mathrm{dc}}
\end{array}\right]+\left[\begin{array}{cc}
\frac{-1}{\mathrm{~L}_{\mathrm{s}}} & 0 \\
0 & \frac{-1}{\mathrm{~L}_{\mathrm{s}}} \\
0 & 0
\end{array}\right]\left[\begin{array}{c}
\mathrm{E}_{\mathrm{tR}} \\
\mathrm{E}_{\mathrm{tI}}
\end{array}\right]
$$

\section{FUZZY-LOGIC (FL) BASED COORDINATED CONTROLLER DESIGN}

FL is considered as one of the most practically effective methodologies for exploiting the systems' qualitative knowledge to design a controller [24, 25]. Moreover, there is no need for the systems' mathematical model in FL controllers to be included. They are robust and cover a wide range of operating conditions. Furthermore, with using FL controllers, traditional FACTS POD controller's merits are maintained. The disadvantages of PI controller is the inability to react to abrupt changes in the error signal, $\varepsilon$ because it is only capable of determining the instantaneous value of the error signal without considering the change of the rise and fall of the error which in mathematical terms is the derivative of the error signal, denoted as $\Delta \varepsilon$.

Through the fuzzification process, the inputs $(\varepsilon$ and $\Delta \varepsilon)$ FL subsets are well-defined as (-B, -M, $-\mathrm{S}$, $\mathrm{Z},+\mathrm{S},+\mathrm{M},+\mathrm{B})$. Where each input is fuzzified into $7 \mathrm{FL}$ variables, the FL coordinated controller has 49 rules. Table 1 represents the inference rule base. Control signals are generated by the FL controller.

\begin{tabular}{llllllll}
\multicolumn{7}{c}{ Table 1. FLC Rule Base } \\
\hline$\varepsilon / \Delta \varepsilon$ & $-\mathrm{B}$ & $-\mathrm{M}$ & $-\mathrm{S}$ & $\mathrm{Z}$ & $+\mathrm{S}$ & $+\mathrm{M}$ & $+\mathrm{B}$ \\
$-\mathrm{B}$ & $+\mathrm{B}$ & $+\mathrm{B}$ & $+\mathrm{M}$ & $+\mathrm{M}$ & $+\mathrm{S}$ & $+\mathrm{S}$ & $\mathrm{Z}$ \\
$-\mathrm{M}$ & $+\mathrm{B}$ & $+\mathrm{B}$ & $+\mathrm{M}$ & $+\mathrm{M}$ & $+\mathrm{S}$ & $\mathrm{Z}$ & $-\mathrm{S}$ \\
$-\mathrm{S}$ & $+\mathrm{M}$ & $+\mathrm{M}$ & $+\mathrm{M}$ & $+\mathrm{S}$ & $\mathrm{Z}$ & $-\mathrm{S}$ & $-\mathrm{M}$ \\
$\mathrm{Z}$ & $+\mathrm{M}$ & $+\mathrm{S}$ & $+\mathrm{S}$ & $\mathrm{Z}$ & $-\mathrm{S}$ & $-\mathrm{M}$ & $-\mathrm{M}$ \\
$+\mathrm{S}$ & $+\mathrm{S}$ & $+\mathrm{S}$ & $\mathrm{Z}$ & $-\mathrm{S}$ & $-\mathrm{S}$ & $-\mathrm{M}$ & $-\mathrm{M}$ \\
$+\mathrm{M}$ & $+\mathrm{S}$ & $\mathrm{Z}$ & $-\mathrm{S}$ & $-\mathrm{M}$ & $-\mathrm{M}$ & $-\mathrm{M}$ & $-\mathrm{B}$ \\
$+\mathrm{B}$ & $\mathrm{Z}$ & $-\mathrm{S}$ & $-\mathrm{S}$ & $-\mathrm{M}$ & $-\mathrm{M}$ & $-\mathrm{B}$ & $-\mathrm{B}$ \\
\hline
\end{tabular}

\section{STATCOM EXPERIMENTAL CONTROL SYSTEM}

The MATLAB/SIMULINK implementation of the fuzzy controller for one- ph is shown in Figures 5, 6. In Figures 7, 8 one-ph of PI controller is shown. The control system mission decreases or increases the $\mathrm{Vdc}$ on capacitor in order for the generated AC voltages to have the approved amplitude which is used for required Q. In case if the generated Vac remains in phase with Vsystem at STATCOM bus, both losses inverter and transformer will be generated. 


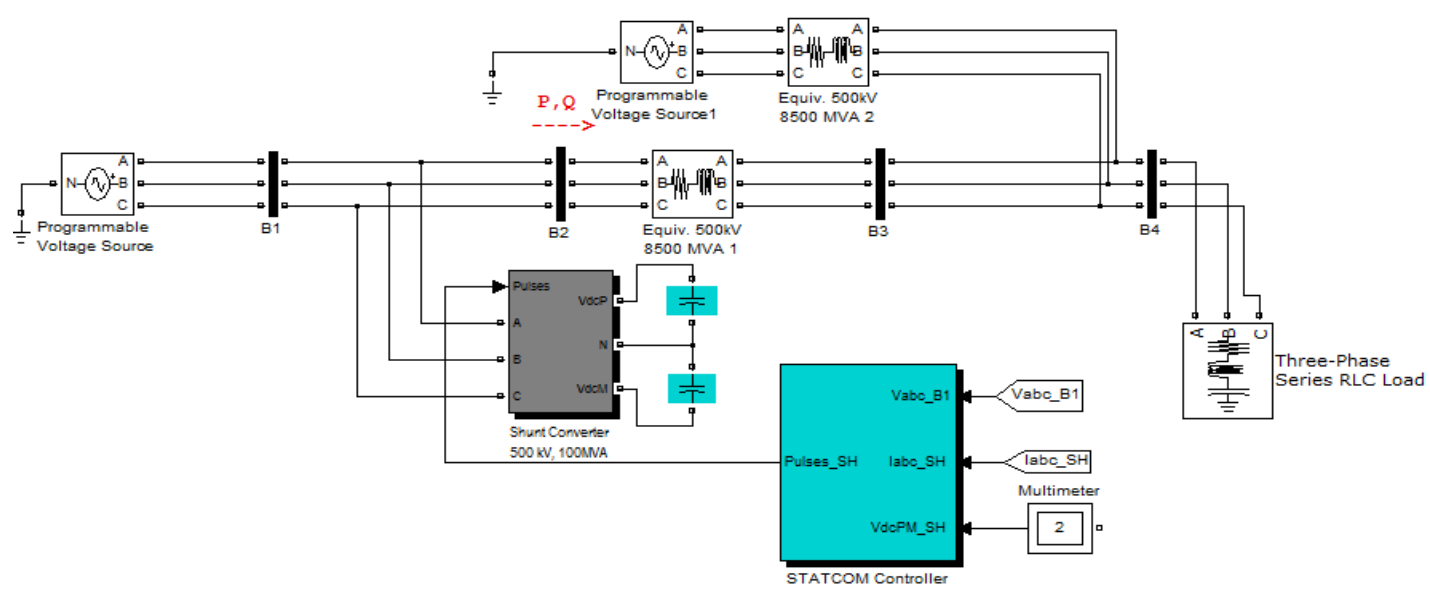

Figure 5. The studied system configuration

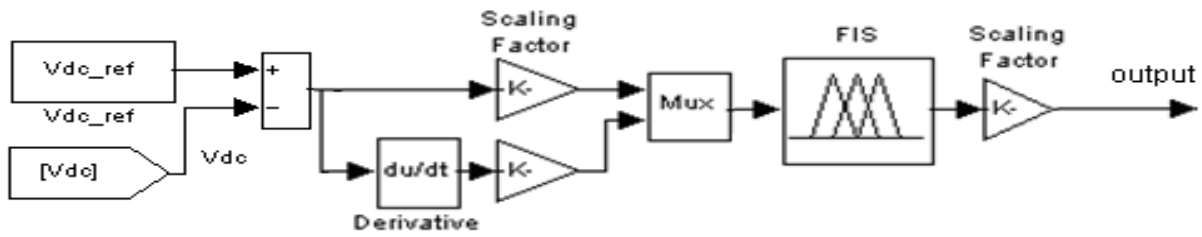

Figure 6. Simulink model of FLC

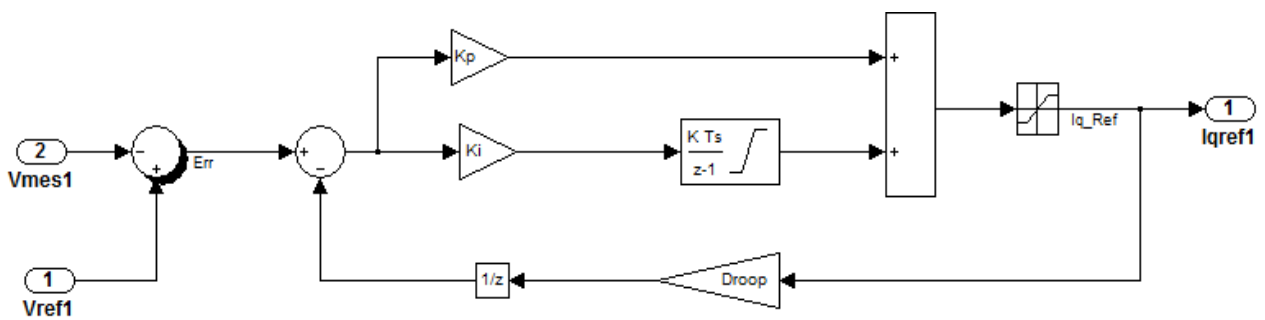

Figure 7. Simulink model of PI controller for Iqref

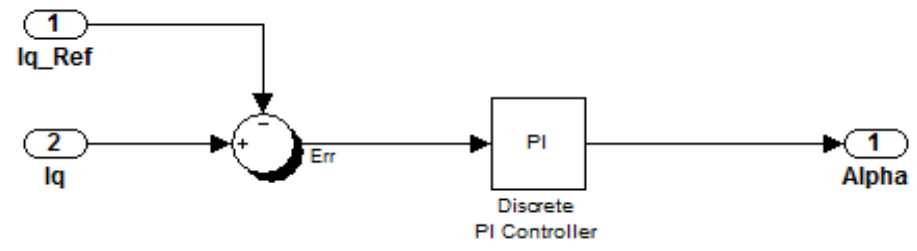

Figure 8. Simulink model of PI controller for Alpha

\section{EXPERIMENTAL RESULTS}

STATCOM controls V at bus bar B1 by overprotective the generated or absorbed Q. Which its variant can be obtain by changing the $\mathrm{V}$ at the dc-bus. The converter drives at conduction- angle(sigma) with constant value equal to $172.5^{\circ}$ and consist of 4 three level parallel converters, so a quasi sin 48 step V waveform will be generated. 47th and 49th are first momentous harmonics. The STATCOM is worked as a VS of Q. This simulation is evaluated the performance of the STATCOM with and without proposed fuzzy 
controller in two tasks, the first task in steady state condition. Only one phase is shown because the sake of clarity and simplicity. The proposed system configuration of Figure 6 has been simulated by Simulink of Matlab.

The simulation taken about $0.15 \mathrm{sec}$ until to steady state. Voltage at B1(Vs), current at B1(Is) and Vstatcom are shown in Figure 9. STATCOM operate in two modes (inductive and capacitive) in the inductive mode Vs is higher than Vstatcom in $(\mathrm{pu})$ and $\mathrm{V}$ is leading $\mathrm{I}$ by $90^{\circ}$. On the contrary, in the capacitive mode Vs is lower than Vstatcom in $(\mathrm{pu})$ and $\mathrm{V}$ is lagging $\mathrm{I}$ by $90^{\circ}$. Thus, STATCOM will be generate Q. In Figure 10, Q is generating in capacitive-mode and absorbing in inductive -mode by the STATCOM. In Figure 11 the STATCOM remains the voltage constant at $1.05 \mathrm{pu}$ in inductive and capacitive mode.
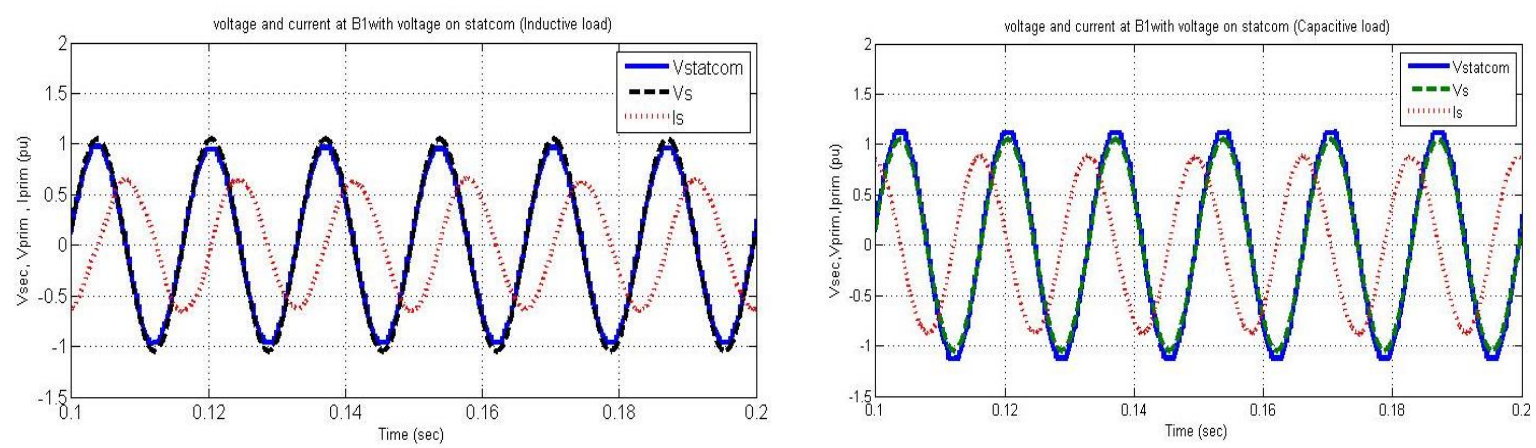

Figure 9. Voltage and current at B1with voltage on statcom (Inductive and capacitive load)
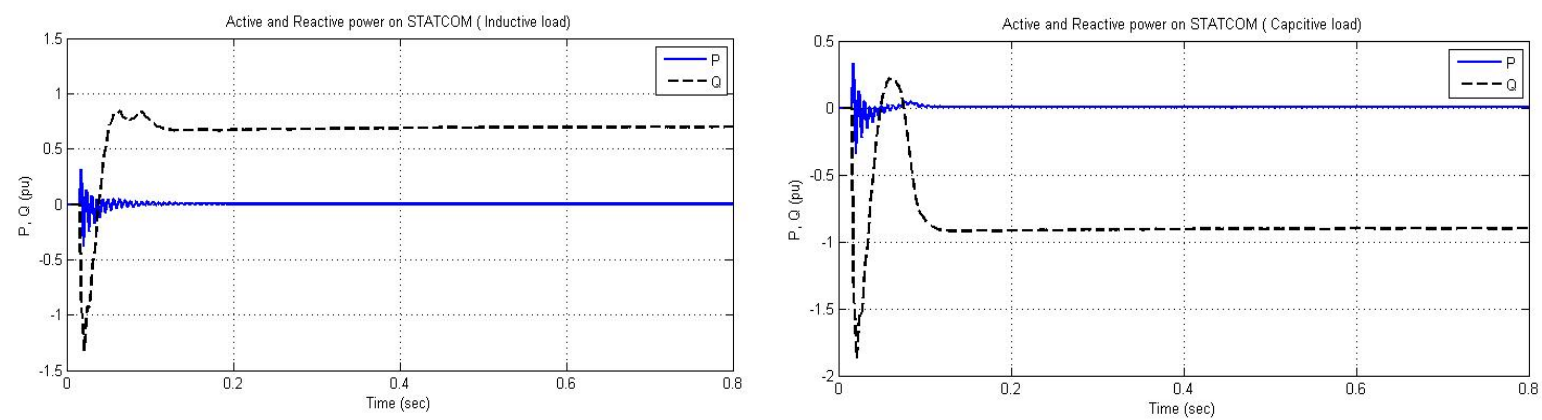

Figure 10. Active and Reactive power on STATCOM (Inductive and capacitive load)
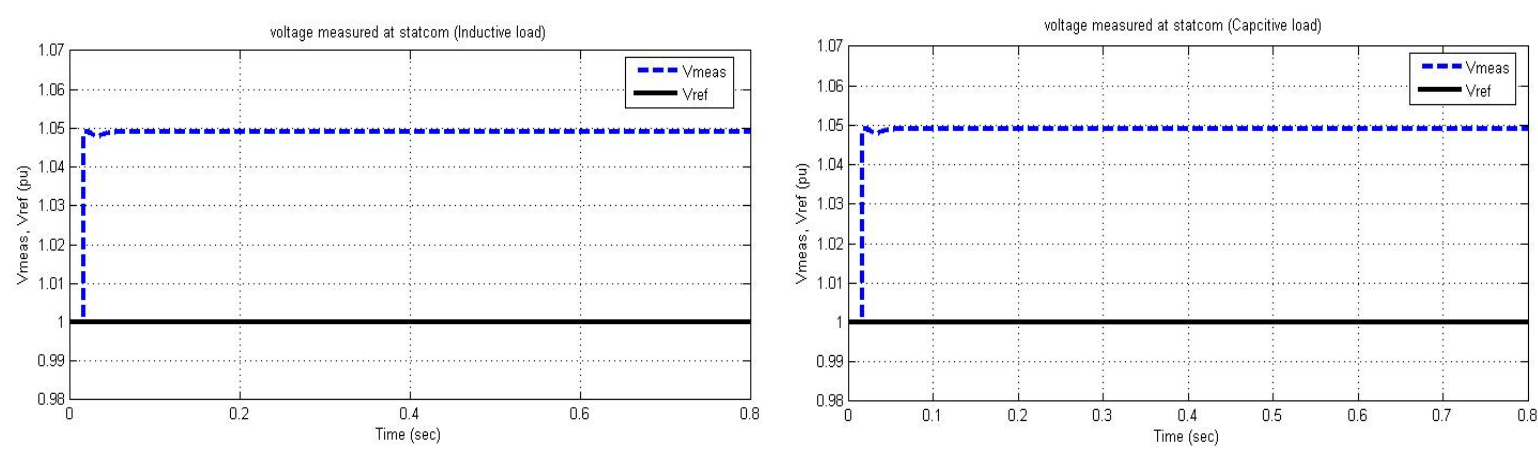

Figure 11. Voltage measured at STATCOM with voltage reference (Inductive and capacitive load)

To keep a small $\mathrm{P}$ flow compensating in inductive and capacitive mode, converter and transformer losses require a stead state value of alpha $\left(\alpha=0.5^{\circ}\right)$ which is the phase shift illustrated in Figure 12 . The + ve 
and -ve voltages of the DC bus are enforced to be equal by the dc Balance Regulator module, as shown in Figure 13. The values are $\mathrm{Vdc}=21.7 \mathrm{KV}$ (capacitive load) and $\mathrm{Vdc}=19.3 \mathrm{KV}$ (inductive load). From the above-mentioned figures, the dynamic response of STATCOM is very good in steady state case while the voltage on STATCOM remains constant. Also, the alpha becomes close to zero in addition to absorbing or generating reactive power as the operation mode.
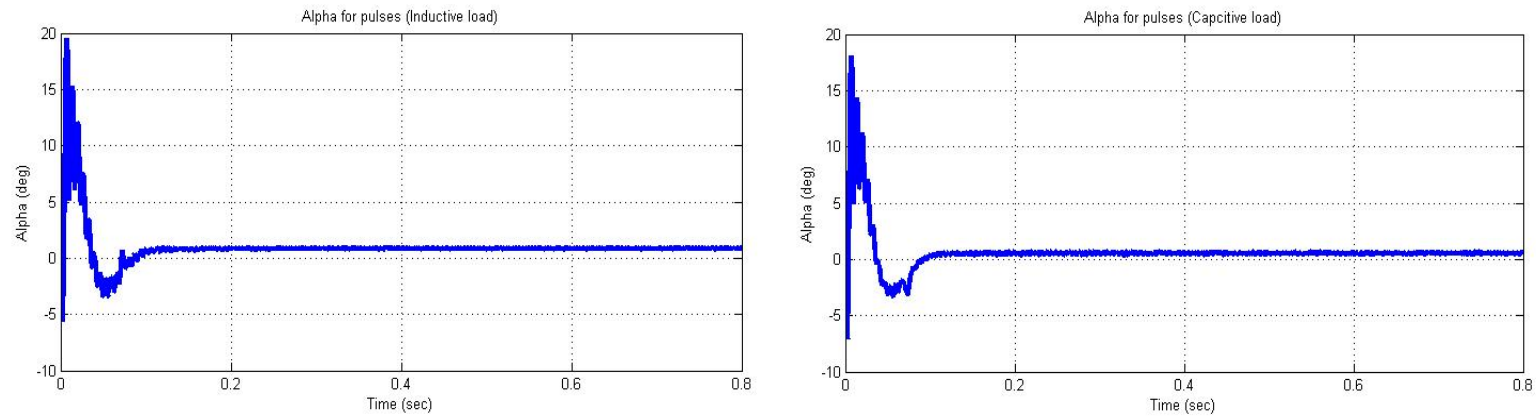

Figure 12. Alpha for inverter pulses (Inductive and capacitive load)
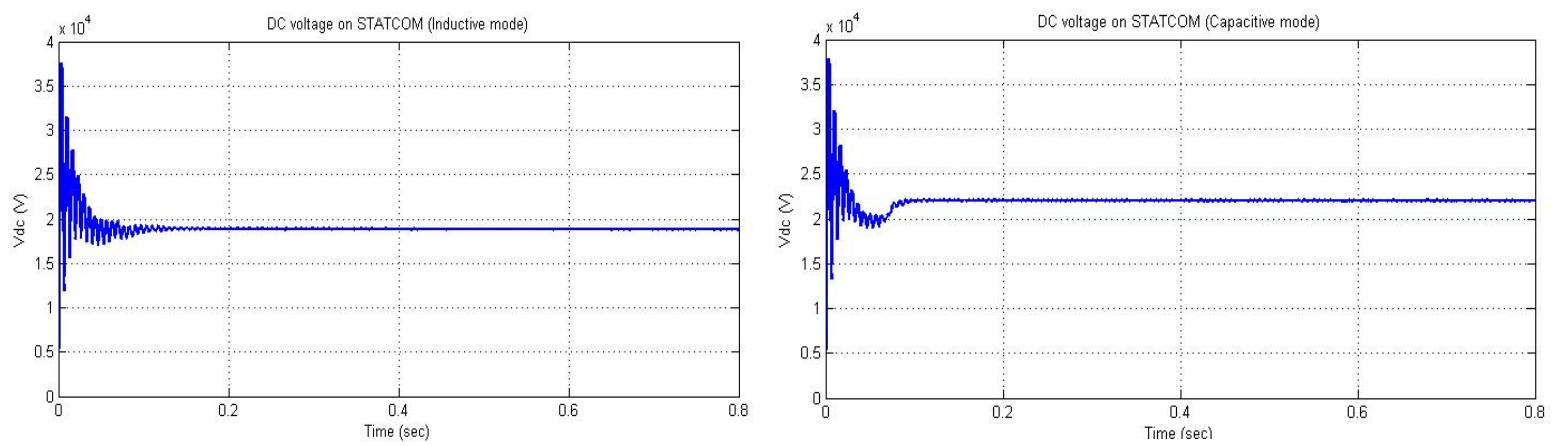

Figure 13. DC voltage on STATCOM (Inductive and capacitive load)

The second task of the proposed new controller in STATCOM control during transient state is to decrease or increase the Vdc on the capacitor. therefore, the generated Vac has the suitable amplitude used for necessary $\mathrm{Q}$ and keeps it in phase with $\mathrm{V}_{\text {system }}$ at the STATCOM bus en route to absorb or generate Q only (exclusive of small $\mathrm{P}$ required by inverter and transformer losses). At the beginning, set $\mathrm{Q}$ by zero until $\mathrm{t}=0.4 \mathrm{sec}$., then increase $\mathrm{Q}$ to be $-0.9 \mathrm{pu}$ (in this case $\mathrm{Q}$ is generated by STATCOM). When $\mathrm{t}=0.6 \mathrm{sec}$., reverse $\mathrm{Q}$ to be $0.7 \mathrm{pu}$ (in this case $\mathrm{Q}$ is absorbed by STATCOM). Figures 14, 15 and 16 show the response for the new controller in STATCOM and the comparison between the STSTCOM with or without new controller (explained in Table 2).
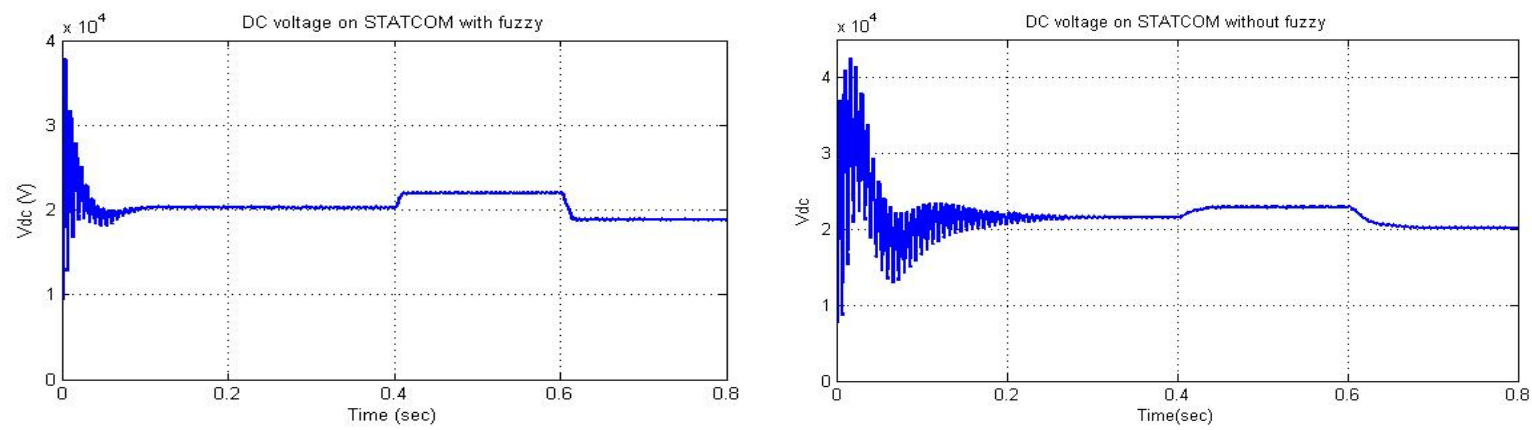

Figure 14. DC voltage on STATCOM with or without and new controller 
Table 2. Comparison between the STSTCOM with or Without and New Controller

\begin{tabular}{lccc}
\hline & parameter & With new controller & without \\
\hline DC voltage & Time $(\mathrm{sec})$ & 0.12 & 0.25 \\
& Max. overshoot & $3.8 \mathrm{KV}$ & $4.2 \mathrm{KV}$ \\
Quadrature current & Time $(\mathrm{sec})$ & 0.1 & 0.18 \\
& Max. overshoot & 2.7 & 6.2 \\
Reactive power & Time (sec) & 0.16 & 0.22 \\
& Max. overshoot (+) & 0.5 & 1.2 \\
& Max. overshoot (-) & 1.6 & 5 \\
\hline
\end{tabular}
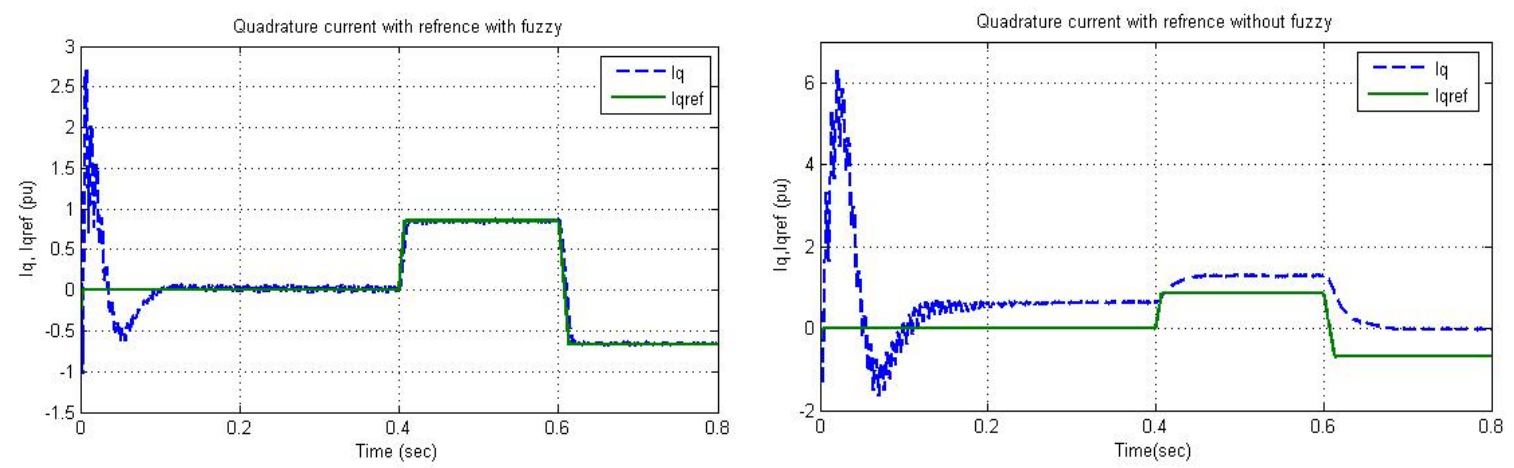

Figure 15. Quadrature current on STATCOM with or without and new controller
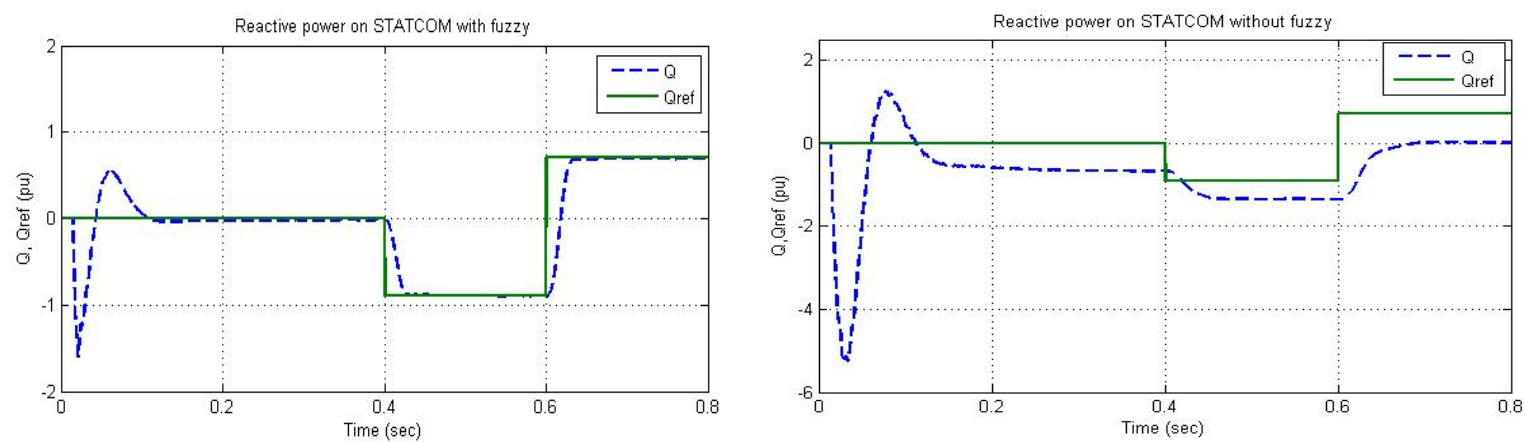

Figure 16. Reactive power on STATCOM with or without and new controller

\section{CONCLUSION}

In this paper a new controller (FLC) in addition to the PI controller control the Vdc bus parameter of a STATCOM in compensation mode. The primary function of the STATCOM is to be a reactive power controller that is accomplished by injecting the consequent compensating I into the T.L and extracting the Iq of load current. Proper Id component adjust the DC-bus voltage. One of the major advantages of the proposed scheme was to combine the PI and FLC. It becomes more sensitive to the system parameters' variation. Additionally, it is characterized by an insignificant time response. The anticipated controller has some advantages derived from analysis of simulation results (e.g tough robustness to the unexpected load variations, high precision of tracking the Vdc reference and high-speed dynamic response).

\section{REFERENCES}

[1] Abdel-Akher M., Nor K. M., Abdul-Rachid A.H. "Three-phase power-flowmethods using sequence components." IEEETrans.Power Systems. August 2005:vol. 20, no. 3, pp. 1389-1397.

[2] Arulampalam A., Ekanayake J. B., Jenkins N. "Application study of a STATCOM with energy storage." lEE Proceedings -Generation, Transmission and Distribution. May 2003: vol. 150, no. 3, pp. 373-384.

[3] Azbe V., Gabrijel U., Povh D., Mihalic R. "The Energy Function of a General Multi machine System With a Unified Power Flow Controller.” IEEE Trans. Power Systems. August (2005); Vol. 20,No. 3, pp. 1478-1485. 
[4] Birt K. A., Graff J. J., McDonald J.D., El-Abiad A. H. "Three phase load flow program." IEEE Trans. Power App. System. Jan/Feb. 1976; vol. 95, no. 1, pp. 59-65.

[5] Boroujeni, S. M. S., Hemmati, R., Delafkar, H., Behzadipour, E. "Voltage Support and Stability Enhancement using STATCOM.” American Journal of Scientific Research, Euro Journal Publishing. 2011.

[6] Erinmez I. A. Foss A. M., (eds.). "Static Synchronous Compensator (STATCOM)." Working Group 14.19. CIGRE Study Committee 14. August 1999; Document No. 144.

[7] Garg A., Agarwal S. K. "Voltage Control and Dynamic Performance of Power Transmission System using STATCOM and its Comparison with SVC." International Journal of Advances in Engineering and Technology. January 2012.

[8] Haque M. H. "Application of UPFC to Enhance Transient Stability Limit." Power Engineering Society General Meeting. June (2007);pp. 1-6.

[9] Hingorani, N.G. "Power Electronics and Flexible AC Transmission System." IEEE Power Engineering review. July 1988.

[10] Januszewski M., Machowski J., BialekJ. “Application of the direct Lyapunov Method to improve damping of Power swings by Control of UPFC." IEE Proceedings Generation, Transmission\& Distribution. March(2004) ;Vol. 151, No.2, pp. 252-260.

[11] Kazemi A., Sohrforouzani M. V. "Power system damping using fuzzy controlled facts devices." Electrical Power and Energy Systems 28. (2006) ;349-357.

[12] Mamdani, E. H. "Twenty years of fuzzy control :Experiences gained and lessons learnt." Proceedings of the 2nd IEEE International Conference on Fuzzy Systems.1993; (pp. 339-344), San Francisco, CA.

[13] Kishore P. V., Reddy S. R.. Voltage Sag Mitigation in Eight Bus System using D - STATCOM for Power Quality Improvement. International Journal of Engineering Science and Technology.2010; volume 2 (4), 529 - 537.

[14] Kundur P. Power System Stability and Control. McGraw-Hill. 1994; New York.

[15] Limyingcharoen S., Annakkage U. D., Pahalawaththa N. C. "Fuzzy logic based unified power flow controllers for transient stability improvement." IEE Proceedings Generation, Transmission\& Distribution. 1998; Vol. 145, No.3, pp. 225-232.

[16] Mahdad, B., T. Bouktir, K. Srairi. “A three-phase power flow modelization: a tool for optimal location and control of FACTS devices in unbalanced power systems." The 32nd Annual Conference of the IEEE Industrial Electronics Society.2006; Conservatoire National des Arts \&Metiers Paris, FRANCE, Page(s): 2238 - 2243, 1-4244-0136-4/06.

[17] Mathur R. M., Rajiv K. V. "Thyristor Based FACTS Controllers for Electrical Transmission Systems." IEEE press series on Power Engineering, John Wiley \& Sons LTD. 2002.

[18] Manuel S. Alvarez-Alvarado, Dilan Jayaweera. "Smart Maintenance Model for Operational Planning of Static Synchronous Compensators." IEEE Milan PowerTech. 2019

[19] Sadeghzadeh S. M., Ehsan M., Said N. H., Feuillet R.. "Improvement of Transient Stability Limit in Power System Lines Using Fuzzy Control of FACTS Devices." IEEE Transactions on Power Systems. 1998; Vol. 13, No.3.

[20] Srivasta S. K. "Advanced Power Electronics Based Facts Controllers and Overview." Asian Power Electronics Journal. December 2010; volume 4, No. 3.

[21] Swaroopan NM. J., Somasundaram P. "Transient Stability Enhancement with UPFC." IET-UK International Conference on Information and Communication Technology in Electrical Sciences (ICTES). Dec. (2007); pp. 510- 516.

[22] Yang Z., Shen C., Zhang L., Crow M. L., Atcitty S. "Integration of a StatCom and battery energy storage." IEEE Transactions on Power Systems. May 2001;vol. 16, no. 2, pp. 254-260.

[23] HyunWoo Lee, Jung-Wook Park. "An Improved STATCOM based on Hybrid Modular Multilevel Converter." 34th International Technical Conference on Circuits/Systems, Computers and Communications (ITC-CSCC). 12 August 2019

[24] Zhang X.P., Rehtanz C., Pal B. "Flexible AC Transmission Systems: Modelling and Control." Springer-Verlag Berlin Heidelber. 2006.

[25] A. Y. Hassan, S. A. E. Wahsh and M. A. E. Badr. dSP ACE DS 1202 "Based Real Time Implementation of Cuckoo Search Optimized FDTC of PMSM." Twentieth International Middle East Power Systems Conference (MEPCON). 2018; Cairo, Egypt, pp. 1126-1133. 